Public Health Centre and the administration of the Joint Pacific Public Health Authority and of the Medical Department of Fiji. In addition, it is proposed to use the buildings of the existing Colonial War Memorial Hospital, erected in 1923 to commemorate the fallen in the War of 1914-18, as a new and wellequipped isolation hospital. There will also be four regional hospitals, and the provincial hospitals will be improved. Modern research laboratories, built in 1936 with the help of the Rockefeller Foundation and of Lord Trent, are also available and adequate for present needs.

of special general interest in view of the precautions which are being taken, all over the world, against the spread of disease in these days of fast transport and aerial travel, are Dr. McGusty's remarks about malaria. Malaria-carrying mosquitoes did not reach Fiji even in the days of sailing ships, although no special precautions were taken to prevent their entry. Dr. MeGusty suggests that the southeast trade winds delayed the ships and washed their decks with salt spray, and also that their water-casks were always filled from fast-running streams in which mosquito larvæ did not develop. But the present War has brought an immense volume of traffic by sea and air, and it is a great tribute to the British and United States navy and army authorities that the precautions they have taken have so far kept malaria out of Fiji. How fatal to Fijians its entry might be, and how vital these precautions are, will be realized by those who have read the note in Nature of May 20,1944, p. 625, on the importance of all human parasites in times of war, and on the very serious results which may follow their attack on populations which are not accustomed to them.

Council Paper No. 3, which is a report on the public health and medical services of Fiji made by Dr. Watt, director general of health, New Zealand, and Miss Lambie, director of nursing, New Zealand (the Watt-Lambie Report), illustrates the co-operation between Fiji and New Zealand which the Legislative Council of Fiji wishes to encourage. This report is not merely a report on the health of Fiji ; it is also a valuable essay in modern public health practice. Plague and smallpox are, it points out, constant menaces to countries in the Pacific. They can be combated by the quarantine system and measures for rat control recommended by the report and by vaccination for smallpox. The importance of keeping out anopheline mosquitoes is emphasized. The other quarantinable Fijian diseases are yellow fever, cholera and typhus. The recent discovery of the efficacy of $D D T$ as a means of killing the lice which transmit typhus and its successful application to large numbers of people in Naples recently should greatly assist the control of this disease in Fiji as well as elsewhere in the world, if, indeed, it does not check its ravages completely. The principal infectious diseases in Fiji are tuberculosis, typhoid fever, dysentery, diphtheria (which is not a major problem) and yaws and hook-worm (which are being well handled).

Tubereulosis is a serious problem in all native races and this report recommends mass miniature radiography, as well as the other measures usually used for its control. Local housing standards are usually good, but it is feared that tuberculosis may increase as the number of town dwellers increases. The pasteurization of milk in the larger communities, or in some places the boiling of it, are recommended, and this should help in the control of tuberculosis as well as that of typhoid and some other illnesses. The control of typhoid and dysentery depends upon safe milk, water and food and on efficient sanitation and general cleanliness. Better supervision of meat supplies and of milk production and improvement of housing, drainage and sewage disposal are required in some areas. The report discusses in some detail the organization and staff of the medical department, the maternal and child-welfare services and the existing hospital services (reports on the last-named constitute an appendix to the report). Other sections of the report deal with the medical, dental and nursing services and with medical and health education. The criticisms of these are, in the main, met by the scheme of reorganization outlined above.

The authors of the report think that Fiji will become a natural centre for medical research and education for the various island groups of the South Pacific. Its excellent climate and freedom from malaria and other tropical diseases should help this development.

Everyone will wish success to the medical authorities of Fiji in the carrying out of this beneficent scheme. The peoples of these island groups deserve all that we can do for them when, before very long, their sunny land will be freed from the shadow which has recently menaced their future. G. IAAPAGE.

\section{FEDERAL ACTIVITY IN AMERICAN EDUCATION}

$\mathrm{T}$ is not easy, for a non-American, to understand why each of the forty-eight States of America should be educationally autonomous, and why therefore it is difficult for anyone to speak for American education as a whole. This is but one aspect of the opposition between Federal Government and State rights - a matter incomprehensible to a person who is unacquainted with the broad lines of American history and has never travelled in the United States. But war is a national effort, and must be conducted by the nation, in this case with powerful collateral effects upon the forty-eight educational systems. Thus the United States Office of Education at Washington, headed by the U.S. Commissioner of Education, is extremely active, and by the use of the funds provided by the Federal Government for educational purposes is able to promote the ends of a nation at war. So much is made clear by the Annual Reports of the U.S. Office of Education 1941-2 and 1942-3, by the pamphlet entitled "Federal Government Funds for Education 1940-1 and 1941-2", and by the official bi-weekly journal Education for Victory, which replaces School Life for the duration of the War, and which is specially addressed to all American youth.

Among the war-time causes aided by the U.S. Office of Education agriculture takes a very prominent place, followed by vocational education, vocational rehabilitation, national defence training, library service, adjustment of college curricula to meet wartime needs, teacher personnel problems, not to speak of a long list of less important subjects.

Another way in which the U.S. Office of Education conveniently speaks for America as a nation is exemplified by pamphlets entitled "Inter-American Education : A Curriculum Guide", and "Education in Cuba". The former represents a concerted effort on the part of the U.S. Olfice of Education to establish a plan for making the study of the other American 
republics an integral part of the curriculum in primary and secondary schools. The latter is one of several basic studies on education in the other American republics planned as a part of a programme to promote better understanding of education in the Latin-American countries and to encourage closer educational co-operation.

The U.S. Office of Education does not limit its educational surveys to the American continent, but extends them to the wider field of what is known as comparative education. A good example is Leaflet No. 69 , which provides a clear and interesting report on "Education in China To-day". The report shows how, despite the invasion of her best developed educational centres, China is to-day demonstrating an unshakable confidence in public education. It seems quite obvious that the Central Office of Education in the United States is doing most valuable work which does not fall within the purview of any one of the forty-eight States.

\section{RESTORATION OF THE LENINGRAD INSTITUTE FOR PLANT CULTURE}

\section{BY IVAN BONDARENKO*}

$\mathrm{B}$ EFORE the War, the Leningrad Institute for Plant Culture had formed a valuable collection of seeds of many species of plants. When the siege of the city began, most of the scientific workers were evacuated into the interior of the U.S.S.R., but the seed collection had to be left behind at Leningrad. As soon as the city was freed, the workers returned.

Johann Eichfeld, who came back with a number of assistants, began re-sorting the collection; in the early spring he sent about ten thousand samples of various seeds to different parts of the Soviet Union with the request that they should be planted and a report on the growth furnished to the Institute. Telegrams have already been received reporting results from the Urals, North Caucasus, the Moscow region and Central Asia; in nearly all cases the results have been normal. This shows that, in the main, the collection has not been disturbed, and that with its help new research can be undertaken and the task of helping the restoration of regions devastated by the Germans can be tackled.

The Institute workers are now busy rebuilding their experimental station, which is situated three miles from Pavlovsk near Leningrad. This was formerly a big experimental farm where there were about two hundred varieties of fruits, three thousand varieties of berry fruits (including the only collection of gooseberries in the U.S.S.R.), about fifty thousand hybrid fruit trees and bushes, and many flowers and decorative plants. The station had cherries which ripen quickly in the short summer of this district, with some very fine varieties of strawberries, blackcurrants, plums and apples.

The German invaders destroyed the greenhouses, laboratories, seed stores, dwelling-houses and other buildings on the station. Many collections of plants were taken away to Germany, and those that were left were badly neglected. People from neighbouring villages and some ex-marines are now helping to rebuild the station.

Under the guidance of Profs. Fedor Teterev and Roman Cordon, houses are being rebuilt and implements repaired. The plantations of shrub fruits and

* Transcribed by $A$. Clifford. the orchards are being dug over. Seed is being prepared for rapid distribution. It is expected that in the autumn of 1944 and the spring of 1945 the Institute will provide farm nurseries with 100,000 strawberry cuttings, 50,000 young fruit trees, 60,000 currant bushes and many other plants. At the same time, rapid distribution of various plants is being organized so that by next summer some $3,000,000$ saplings and cuttings of fruit trees and bushes will be ready. Extensive plans for scientific research work are also being made.

\section{EARTHQUAKES DURING THE SECOND QUARTER OF 1944}

$\mathrm{D}^{\mathrm{t}}$ URING April and May, twenty-six strong earthquakes were registered by the instruments at Toledo (Spain), and ten by the seismographs at Wellington, New Zealand. In addition, twenty-five earthquakes were felt by people in some parts of New Zealand. During April 26-June 25, eight epicentres were determined from instrumental evidence by the United States Coast and Geodetic Survey in co-operation with Science Service and the Jesuit Seismological Association. On April 26 an earthquake originated at $1 \mathrm{~h} .53 \cdot 9 \mathrm{~m}$. G.M.T. from a provisional epicentre at $1^{\circ} \mathrm{S} ., 131^{\circ} \mathrm{E}$. , in western New Guinea. It was registered by the instruments at eleven United States observatories, and also at Toledo and Wellington. An after-shock from the same epicentre had its origin time at $14 \mathrm{~h} .37 .9 \mathrm{~m}$. G.M.T. on April 27. This was registered at Toledo and Wellington and was reported from fifteen other stations in the United States, Australia and the Pacific Islands.

The earthquake of May 6 originated at $0 \mathrm{~h} .13 \cdot 7 \mathrm{~m}$. G.M.T. from an epicentre at $22 \cdot 4^{\circ} \mathrm{N} ., 44 \cdot 8^{\circ} \mathrm{W}$, in mid-Atlantic. It was registered at nine American observatories and at Toledo, but not at Wellington, in any strength. The shock of May 25 at $1 \mathrm{~h} .06 \mathrm{~m} .39 \mathrm{~s}$. G.M.T. originated at $21 \cdot 5^{\circ} \mathrm{S} ., 179 \cdot 0^{\circ} \mathrm{W}$. in the Tonga Islands, with a depth of focus probably greater than $600 \mathrm{~km}$. It has been reported from sixteen observa. tories in the United States, Pacific Islands, New Zealand and Toledo. This earthquake was world shaking, and attained a maximum ground amplitude at Toledo of $45 \mu$. Also on May 25 there occurred another shock at $12 \mathrm{~h}$. $58 \cdot 1 \mathrm{~m}$. G.M.T. This time it was from an epicentre at $3^{\circ} \mathrm{S} ., 152^{\circ} \mathrm{E}$., in New Ireland. It was registered at fourteen stations in the United States, Pacific Islands, New Zealand and Toledo.

On June 16 an earthquake was registered at nine American observatories, and its epicentre as provisionally determined by the U.S. Coast and Geodetic Survey was at lat. $19^{\circ} \mathrm{N}$., long. $105^{\circ} \mathrm{W}$. Its origin time was $21 \mathrm{~h}$. $51 \cdot 5 \mathrm{~m}$. G.M.T. The shock of June 21 originated in the New Hebrides $\left(21 \cdot 5^{\circ} \mathrm{S} ., 169 \cdot 8^{\circ} \mathrm{E}\right.$.) at $10 \mathrm{~h} .58 \cdot 3 \mathrm{~m}$. G.M.T., and that of June 25 originated in mid-Atlantic ( $1^{\circ} \mathrm{S} ., 25^{\circ}$ W.) at $17 \mathrm{~h} .42 \cdot 2 \mathrm{~m}$. G.M.T. according to the determination based on reports from Fordham, Huancayo, San Juan and Spring Hill.

In New Zealand the strongest earthquakes to be felt had strength IV on the modified Mercalli scale. These were reported as follows: April 17 at Porangahau, April 22 at Blenheim, Cook Strait and Wellington, April 30 at Tolaga Bay, May 16 in the Takaka region and May 20 at Rotorua. On May 9 an earth tremor was felt at Wairoa and Napier with scale III, and some inhabitants of Napier again felt. a shock with scale III on May 31 . 